\title{
SOBRE EL DERECHO A MENTIR. VERDAD Y POSVERDAD EN LA COMUNICACIÓN Y LA CONSTRUCCIÓN DE CIUDADANÍA*
}

\author{
THE RIGHT TO LIE. TRUTH AND POST-TRUTH \\ IN COMMUNICATION AND CITIZENSHIP \\ CONSTRUCTION
}

José MAÑón GARIBAY**

\section{Resumen:}

Por un lado, el supuesto de todo sistema moral y jurídico es que el hombre desea su bien, y que la verdad es un bien deseado por sí mismo. Por otro lado, es sabido que la mentira política juega un papel importante (e indispensable) en el ejercicio del poder y en la consecución del bien común, y que por ello muchos filósofos la han recomendado y justificado (hoy y en el pasado). Ante esta paradoja vale preguntar cómo se construye la ciudadanía (toma de decisiones y participación social) a partir de la información falsa y cómo se construyen valores ciudadanos sobre la base del derecho a mentir de los gobernantes, porque es esencial para cualquier democracia la calidad de la información y la consecuente participación social de los ciudadanos.

Primeramente, se expondrá la justificación de la mentira en tres grandes pensadores de la filosofía occidental (Platón, Maquiavelo y Weber); después, se desarrollará la interpretación marxiana al respecto, y, por último, se dilucidará la manera como hoy día afecta la mentira (y el derecho a mentir) a la comunicación y construcción de valores ciudadanos.

* Este artículo fue recibido el 18 de octubre de 2018, y aceptado para su publicación el 20 de enero de 2020.

** Investigador de tiempo completo en el Instituto de Investigaciones Jurídicas, garibay1@unam.mx.

Problema. Anuario de Filosofía y Teoría del Derecho, núm. 14, enero-diciembre de 2020, pp. 285-313 Ciudad de México, ISSN 2007-4387, se distribuye bajo una Licencia Creative Commons Reconocimiento-No Comercial-Sin Derivados 4.0 Internacional (CC BY-NC-ND 4.0). 
JOSÉ MAÑÓN GARIBAY

\title{
Palabras clave:
}

Filosofía; ciudadanía; verdad; posverdad; democracia; derecho a la información; participación ciudadana.

\begin{abstract}
:
On the one hand, the assumption of every moral and legal system is that man desires his own good and that truth is a good desired by himself. On the other hand, it is known that political lies play an important (and indispensable) role in the exercise of power and the achievement of the common good, and that for this reason many philosophers have recommended and justified them (today and in the past). Faced with this paradox, it is worth asking how citizenship (decision-making and social participation) is built on false information and how citizen values are built on the basis of the rulers' right to lie. Because the quality of information and the consequent social participation of citizens is essential to any democracy.

First, the justification of the lie will be exposed in three great thinkers of Western philosophy (Plato, Machiavelli and Weber); then, the Marxian interpretation will be developed in this respect. And finally, the way in which lies (and the right to lie) affect the communication and construction of citizen values today will be elucidated.
\end{abstract}

Keywords:

Philosophy; Citizenship; Truth; Post-Truth; Democracy; Right to Information; Citizen Participation. 
SOBRE EL DERECHO A MENTIR. VERDAD Y POSVERDAD...

SUMARIO: I. Introducción. II. El carácter de la comunicación política. III. La dinámica de construcción de la realidad social y la posverdad. IV. El valor fetiche de la comunicación política. V. La construcción de los valores ciudadanos a través de la comunicación política. VI. Conclusiones: comunicación política, posverdad y ciudadanía. VII. Bibliografía.

\section{INTRODUCCIÓN}

El 30 de noviembre del 2017, el portal del Instituto Nacional Electoral de México (INE) anunció que se transmitirían sesenta millones de spots publicitarios, difundidos entre diciembre de 2017 y el 4 junio de 2018, por 2,500 estaciones de radio y televisión (sin Internet), con el fin de divulgar los programas políticos de partidos y candidatos, así como la información electoral del mismo INE. Si a éstos se suman los veintidós millones de spots transmitidos durante las precampañas e inter-campañas, entonces el resultado es de 82 millones de spots, o sea, quinientos mil anuncios diarios. ${ }^{1}$

Ante este bombardeo publicitario, se plantea la pregunta sobre el papel de la comunicación política en la construcción de la conciencia y valores cívicos, así como sobre la promoción de la participación ciudadana, tomando en cuenta no sólo la cantidad, sino a la vez la veracidad de los mismos. En las pasadas elecciones, todas las campañas se circunscribieron a descalificar al oponente, con dichos como: "ser un peligro para México", "pertenecer a la mafia del poder" o "estar al servicio de los fifís". Las campañas negativas utilizaron indiscriminadamente la mentira, al grado que fue necesario crear una sección periodística dedicada a verificar la información política. ${ }^{2}$ Pese a esto, no hay que perder de vista que en la construcción de

1 Plan y calendario oficial del proceso electoral federal 2017-2018. Recuperado de: https://repositoriodocumental.ine. $m x / x m l u i /$ bitstream/handle/123456789/935 39/CGex201709-05-ap-1-anexo.pdf?sequence=2\&isAllowed=y. Consultado el 16 de agosto de 2018.

2 Animal Político, periódico en línea. Recuperado de: https://www.animalpolitico. com/tag/verificado-2018/. Consultado el 1o. de agosto de 2018. 
JOSÉ MAÑÓN GARIBAY

la realidad social no sólo juega un papel la información veraz, sino también la mendaz. Por ello, vale preguntar por la justificación e impacto de la misma.

1. ¿Cómo afecta la mentira en la opinión política de los ciudadanos?

2. ¿Afectan positiva o negativamente, i. e., a favor o en contra de un candidato o partido, a favor o en contra de la participación política?

Estas dos preguntas adquieren relevancia cuando en nuestros tiempos se observa una proliferación viral de la información, así como de los medios para comunicarla. Con ello, también se ha acrecentado la preocupación por la ética y la probidad, debido a los artilugios modernos para descomponer la veracidad de la información en sus distintas variantes de mentira, a saber: como manipulación y/o supresión de la información y/o exceso de la información. En esto Platón es contemporáneo nuestro al considerar, por un lado, la información verídica, y el hecho de comunicarla con objetividad, como una virtud, y, por otro lado, por haber defendido la mentira noble a riesgo de contradecirse con la vocación del filósofo, además de disipar la unidad y confianza de la comunidad. Platón explica que para gobernar no es suficiente la verdad pura y dura, sino también la persuasión; comunicar la verdad y convencer de ella son dos cosas distintas. De esta manera, el problema está a la vista: si la mentira es un ingrediente de la comunicación política, entonces la relación gobernante-gobernados está quebrantada de origen.

Para el siguiente análisis se utilizará preferentemente el libro del austriaco Peter Berger y el alemán Thomas Luckmann, La construcción social de la realidad, ${ }^{3}$ publicado en la segunda mitad del siglo XX. Este libro se convirtió desde su publicación en un clásico de la filosofía y de la sociología del conocimiento, porque fundó la escuela del constructivismo social con base en las ideas fenomenológicas de Alfred Schütz.

3 Berger, L. Peter y Luckmann, Thomas, Die gesellschaftliche Konstruktion der Wirklichkeit, Frankfurt am Main, ediciones Fischer, 2001. 
El presente escrito se engancha a esta tesis y la desarrolla en relación con el papel de la comunicación política y los medios de comunicación en la construcción de la conciencia (o falsa conciencia) de la realidad social. La pregunta que guía esta investigación puede formularse así: ¿qué papel juega la comunicación política en la construcción del sistema social de valores? La finalidad no es describir en general los procesos sociales que permiten la construcción de ámbitos emergentes, ${ }^{4}$ sino únicamente establecer la influencia de la publicidad y medios de comunicación en la formación de la conciencia (o falsa conciencia), el sistema de valores del individuo y su respectiva participación social.

En las siguientes páginas se presentará primeramente la justificación de la mentira política en la filosofía, y subsecuentemente su elucidación marxiana como falsa conciencia. Después, se verá el carácter de la publicidad (política) y la dinámica por la que se aparta de las necesidades informativas hasta transfigurarse en un valor fetiche. Y, por último, se analizará la forma en que el fetiche se constituye en un factor decisivo para la construcción de la realidad social (como falsa conciencia responsable de la alienación social).

\section{Sobre el derecho a mentir}

Se ha considerado la mentira como un instrumento necesario para la actividad política y como aquella que tiene lugar entre el gobernante y el gobernado. Porque no toda mentira expresada en la arena política es una mentira política. No constituye una mentira política la de los poderes fácticos (por ejemplo, los consorcios mineros) disimulando la devastación ecológica de sus empresas. Tampoco la mentira útil, bélica o de espionaje, que oculta las verdaderas intenciones frente al enemigo para ganar la delantera. Ni mienten los políticos cuando censuran la información sobre las investigaciones judiciales que llevarán al arresto de bandas delincuenciales. $\mathrm{Ni}$

4 Ámbitos o cualidades emergentes en un concepto usado en teoría de sistemas complejos para designar a las propiedades que surgen del funcionamiento colaborativo de los miembros de un sistema (de cualquier tipo que sea: neuronal, social, químico, etcétera). 
JOSÉ MAÑÓN GARIBAY

siquiera la mentira entre políticos que tiene por fin medrar en la lucha por el poder es aquí aludida. La mentira política es aquella que pronuncia el político a los gobernados con el fin de resguardar el "bien público".

Sin embargo, para muchos el fin no justifica los medios, y por eso es necesario encontrar otras razones que expliquen su empleo. ${ }^{5}$ Max Weber, en su libro La política como profesión, ${ }^{6}$ hace referencia al Gran Inquisidor ${ }^{7}$ de Dostoievski y al problema de justificar cualquier medio por el fin, lo que disociaría los principios de las responsabilidades éticas. Pero tampoco acepta la opinión de su colega F. W. Förster y rechaza la ingenuidad de pensar que del bien solamente se sigue el bien, e invitó por ello a dilucidar qué fines justifican qué medios y cuáles no.

A lo largo de la historia de la filosofía no ha faltado quien lo haya intentado, como Platón (427-347), Nicolás Maquiavelo (1469-1527), Max Weber (1864-1920) o Leo Strauss (1899-1973). Generalmente se olvida en este listado a Karl Marx (1818-1883) y su idea de historia religiosa (mentira) y falsa conciencia (engaño), propuestas para explicar las estrategias políticas, en las sociedades estratificadas por privilegios, y donde es necesario el control de los gobernados vía alienación y mentira.

\section{A. Platón}

La mentira noble se encuentra claramente enunciada en el libro III de la República (III, 414b-c). Ciertamente, se ha debatido la tra-

5 "Kalvinismus wieder kannte prinzipiell die Gewalt als Mittel der Glaubensverteidigung, also den Glaubenskrieg, der im Islam von anfang an Lebenselement war". Weber, Max, Politik als Beruf, Stuttgart, ediciones Reclam, 1997, p. 72.

6 Ibidem, p. 73.

7 Weber hace referencia al Gran Inquisidor (Hermanos Karamazov) de Fiódor Dostoievski, porque allí el mismo Jesucristo es enjuiciado por la Inquisición en aras de mantener el poder religioso erigido en nombre de Jesucristo; i. e., se plantea la cuestión de justificar cualquier medio por el fin (a saber: matar a Jesucristo, pese a que él legitima el poder de la Inquisición, con el fin de mantener el poder de la Inquisición). 
ducción de la palabra "mentira" ( $\psi \varepsilon v \delta \delta$ os), y algunos ${ }^{8}$ han propuesto otra distinta (como falsedad o simulación), desechando "mentira" y su carácter intencional de engañar con falsedades, lo que estaría en contra de la filosofía y su compromiso con la verdad y la virtud.

La mentira noble aparece en Platón, primeramente, para persuadir a los reyes-filósofos a tomar las riendas del gobierno; porque ¿cuál sería la razón para interesar a un filósofo en las tareas de gobierno después de haber alternado con las ideas perfectas? ${ }^{9} \mathrm{Ni}$ el castigo ni la remuneración pecuniaria serían suficientes (o incluso posibles), sobre todo cuando para gobernar es requisito amarla: ¿Cómo amarla después de haber visitado el Topus Uranus? (VI. 486a). Entonces hay que encontrar una estratagema mentirosa que los convenza de ser gobernantes. ¿Cuál? Aceptar que todos los hombres son hijos de la madre tierra y que servirla como a la madre carnal es un acto de justicia elemental que implica tratar a todos fraternalmente como iguales (cuenta a parte de que alguien peor podría hacerse cargo del gobierno).

De esta manera, la mentira noble funciona como mito fundacio$n a l^{10}$ que compele al filósofo a aceptar las tareas de gobernante. Sin la mentira noble no ve Platón cómo alguien desearía gobernar la Ca-

8 Para la traducción de pseûdos se ha usado indistintamente mentira o falsedad. Mentira sería quizá el más adecuado en el contexto de la República, donde se trata de una ficción intencional con un propósito noble. Aunque, por otro lado, falsedad es más neutral en tanto que no implica engaño deliberado. Cfr. Arendt, Hannah, "El concepto de historia: antiguo y moderno", en Entre el pasado y el futuro. Ocho ejercicios sobre la reflexión política, Barcelona, Península, 1996, pp. 49-100.

9 En el libro VII de la República, después de narrar la contemplación de las ideas por parte de los filósofos, afirma Sócrates que se debe evitar que los videntes permanezcan en su contemplación, con el fin que vuelvan a la Caverna a cumplir sus tareas (VII. 519d). Con esto, Platón refiere a un concepto de justicia pertinente con las obligaciones recíprocas, en donde cualquiera (que sea justo) reconoce su obligación de corresponder bien con bien, y tratar a sus conciudadanos dando lo mejor de sí (I. 331d-e). Esta teoría de la justicia ya había sido expuesta en el Critón (50d-51). Cfr., Platón, La República, edición bilingüe griego-español de Antonio Gómez-Robledo, México, UNAM, 2000.

10 Según Cassirer, la necesidad de un mito fundacional deviene de la condición simbólica del hombre (y memoriosa; por ejemplo, en la Teogonía de Hesíodo, Mnemosine); cfr. Cassirer, Ernst, Antropología filosófica. México, FCE, 1945, pp. 47 y ss. 
verna después de haber salido de ella y cómo aceptaría la igualdad de los hombres cuando hay evidencia de lo contrario. La mentira noble persuade a costa de contradecirse; porque, por un lado, se necesita que el yo se identifique con el nosotros para fundamentar la unidad social en el amor e igualdad. Para ello estaría el mito de la madre tierra: una sola madre de todos los hombres igualados como hermanos. Pero, por otro lado, se necesita reconocer la desigualdad entre los mismos para la división del trabajo, según un principio vocacional que indica a cada cual lo suyo. Para ello se apelaría a las diferencias resultantes de haber fundido las almas en distintos metales (III. 415a-c: oro, plata y cobre, según Hesíodo). Con esto parecería que la mentira es la única forma de resolver la contradicción evidente entre contemplación filosófica y acción política o entre igualdad fraternal y desigualdad laboral. ${ }^{11}$

El otro aspecto de la mentira noble reside en el beneficio de los gobernados, como cuando se suministra un brebaje (pharmakon) que sabe mal, pero cura al enfermo. Entonces, la mentira tiene la misión (psicológica) de persuadir cuando el solo hecho de transmitir la verdad desnuda no basta (III. 389b-c). En el libro V de la República, hablando de la necesidad de la eugenesia (V. 459a-c), recomienda Platón mentir a los gobernados por su bien, y convencerlos de que sus matrimonios fueron realizados con base en el azar y no en el cálculo del beneficio social. En este segundo caso, la mentira noble dirigida a los gobernados agrega una asimetría entre gobernantes y gobernados, porque estos últimos no deberán mentir a los primeros, de la misma manera que los pacientes no deben mentir a sus médicos, bajo la pena de subvertir el orden (V. 389b-d).

¿Qué justifica la mentira política opuesta al espíritu de la filosofía y su compromiso con la verdad y la virtud? La repuesta se encuentra en la referencia que hace Platón a los poetas Homero y Hesíodo; porque éstos no son atacados en los libros II y III de la República por mentir, sino por decir falsedades sin ningún uso moral. Lo que éstos le adjudican a los dioses son actitudes antimorales que no reditúan

11 Este mito concluye prediciendo el fin de la ciudad cuando "los de alma de bronce" conducen la ciudad (III. 415a-c). Por tanto, no sólo explica la diferencia por especialidad de tareas, sino, además, el peligro de resistirse al llamado vocacional. 
en la educación virtuosa de los ciudadanos. Por ello, siempre hay que "asimilar la mentira a la verdad" lo mayormente posible, o sea, dotar a la mentira de un uso moral (II. 382b-c).

En La República, al comienzo del libro III, Sócrates expone ejemplos de mentiras útiles (III. 389b-c), como el ejemplo del amigo enloquecido al que no se le deben devolver las armas empeñadas porque puede con ellas cometer una locura. La conclusión no es solamente que mentir a los amigos es lícito, sino, además, que la justicia no es devolver lo que a alguien le corresponde (I. 331a-d) cuando hay otro bien superior en juego.

Sócrates y/o Platón deben explicar por qué son necesarias las fábulas y mitos en la educación de la virtud moral, ya que en principio eso representa un contrasentido: enseñar la virtud de manera poco virtuosa; mintiendo (II. 377b-c). Si las mentiras de Homero y Hesíodo son reprochables, porque no tienen uso moral (II. 371e), las de los filósofos son inaceptables, teniendo en cuenta que en el libro VI (485c) Sócrates declara la aversión por la falsedad: el filósofo debe amar la verdad, ¿cómo entonces justificar la mentira del rey-filósofo? La solución transita por la distinción entre la verdad filosófica y la verdad política: la fidelidad del filósofo es con la verdad teórica, y la permisibilidad, con la mentira política. Claro que la aversión por la mentira iría de la mano de la aversión por gobernar: ¿quién que haya estado en el mundo de las ideas quiere ocuparse de la vida pública (res-pública), sobre todo cuando hay que mentir? (VI. 486a).

Siguiendo este tenor, la pregunta puede ampliarse: ¿por qué alguien debería amar la ciudad, por qué promover el bien general antes que el personal? Si Platón propone que sólo se ama a la ciudad gracias al mito fundacional, entonces hay que responder por qué es necesario enseñar la virtud mintiendo.

Tres respuestas son posibles. ${ }^{12} 1$ ) Porque el filósofo debe ajustar la verdad del Topus Uranus a las condiciones de la Caverna; 2) porque debe persuadir de la verdad, y no son tan dañinas las mentiras del discurso como las mentiras del alma (II. 382b-c), y 3) porque pedagógicamente a los niños se les persuade con fábulas o mentiras nobles, con el fin de modelar su alma en la virtud desde edad temprana.

12 Hösle, Vitorio, Moral und Politik, München, C. H. Beck, 1997, p. 769. 
Entonces, la mentira noble que usa el rey-filósofo se justifica por el bien superior de la ciudad (sobre el bien personal), y porque es la única forma de inculcar el amor a la ciudad desde la tierna infancia, no con razones, sino persuadiendo con fábulas o mentiras. ${ }^{13}$

Ciertamente, la mentira noble en Platón no es una cínica estrategia de propaganda política para controlar a las masas; está destinada a los gobernantes y gobernados para acrecentar su espíritu público: es mentira, porque persuade a través de falsedades; pero es noble, ya que trata de alcanzar un fin superior e inducir un comportamiento virtuoso, dirigido al bienestar social antes que al individual.

En el caso de la República de Platón, la idea de hombre, sociedad y gobierno que ampara o justifica la mentira política es la de una desigualdad natural entre los hombres, cuya supervivencia sólo puede tener lugar dentro de un sistema paternalista (que considera al pueblo como menor de edad y necesitado del gobernante-preceptor), y una sociedad orgánica, donde el individuo sólo cuenta como una pieza al servicio del cuerpo social entero. Aquí se legitima la mentira política entendida tanto como ocultamiento de la verdad como afirmaciones intencionalmente falsas.

Haciendo a un lado el mito fundacional, para Platón el primer beneficiario de la mentira noble es el gobernado, y el gobernante sólo en segundo término. En esto difiere su continuador Nicolás Maquiavelo.

\section{B. Nicolás Maquiavelo}

En el ocaso de la Edad Media, Maquiavelo no se interesa en una justificación moral de la mentira tanto como en una descripción de las estrategias para conservar el poder. Por un lado, la mentira política es necesaria para Maquiavelo por la simpleza y estupidez del pueblo, que reclama ser engañado, ${ }^{14} \mathrm{y}$, por otro lado, la mentira es

13 En el libro II de Las Leyes se repite la necesidad de persuadir, incluso echando mano de mentiras.

14 Maquiavelo afirma que "todo arte consiste en representar el papel con propiedad y en saber disimular y fingir; porque los hombres son tan débiles y tan incautos que cuando uno se propone engañar, nunca deja de encontrar tontos que le crean". También cita el ejemplo del papa Alejandro VI, quien se burlaba del pueblo, porque 
necesaria porque los hombres son malos por naturaleza, lo que los contrapone a la verdad entendida como un bien. Si todos los hombres son malos, solamente se les puede gobernar de igual a igual, o sea, respondiendo al mal con el mal.

Ya me guardaría yo bien de dar tal precepto a los príncipes si todos los hombres fuesen buenos; pero como son malos y están siempre dispuestos a quebrantar su palabra, no debe el príncipe ser exacto y celoso en el cumplimiento de la suya; él siempre encontrará fácilmente modo de disculparse por esa falta de exactitud (El príncipe, c. XVIII, 3, p. 117).

Esta maldad natural de todos los hombres exige, además del temor y la fuerza de un Leviatán, de la astucia del gobernante; o sea, de la mentira. Por eso, el gobernante no debe ser fiel a un ideal o promesa, porque esta virtud compromete su poder político.

En este caso, la justificación de la mentira política es por la conveniencia de conservar el poder, de tal manera que el salto del ser al deber no es al ámbito del deber-moral, sino al de la utilidad y oportunidad. De este modo es como afirma Maquiavelo:

... así lo que importa es allanar todas las dificultades para mantener su autoridad; y los medios, sean los que fueren, parecerán siempre honrosos y no faltará quien los alabe. Este mundo se compone de vulgo, el cual se lleva de la apariencia, y sólo atiende a éxito... (El príncipe, c. XVIII, 5, p. 120).

Para Maquiavelo la mentira tiene lugar dentro de una antropología pesimista (el hombre es malo), cerrada o sin esperanza de mejoría, autoritaria, excluyente de la participación política de la mayoría, déspota y elitista, centrada principalmente en el bien del gobernante, quien desea conserva el poder para mantener sus privilegios. $^{15}$

pensaba que no tenía la preparación para enfrentar la verdad. Cfr. Maquiavelo, Nicolás, El príncipe, XVIII, pp. 117 y 118.

15 Strauss, Leo, Meditación sobre Maquiavelo, Madrid, Instituto de Estudios Políticos, 1964, pp. 101 y ss. 
JOSÉ MAÑÓN GARIBAY

\section{Max Weber}

Max Weber no continuó desarrollando las ideas de Maquiavelo, ${ }^{16}$ pero sí las manieristas, y argumentó a favor de la separación entre ética y política. En su citada obra, La política como profesión, diferencia entre una ética de la responsabilidad de otra de los evangelios o convicción ${ }^{17}$ lo que vacía de contenido práctico a los preceptos morales al considerarlos inadecuados en la vida pública de los gobernantes.

Dentro de los preceptos morales impracticables se encuentra la fidelidad a la verdad, porque la actividad política debe ser responsable (ética de la responsabilidad), y por ello estar en condiciones de mentir, si es conveniente. Esta propuesta de Weber, antes de calificarse de inmoral, debe entenderse en contra de Kant y el aspecto formal de los enunciados éticos como guía de la acción moral: o sea, contra el imperativo categórico o el deber por el deber. Lo que debe constituir la guía de la acción política es la reflexión sobre las consecuencias (o fines inmediatos).

Esta recomendación, si bien está en pugna con la ética evangélica o absoluta, no permite el beneficio personal contra el social, porque no permite cualquier cosa, sino sólo perseguir el bien de la comunidad atendiendo a las consecuencias de los actos antes que a los deberes. En la medida en que el espíritu pragmático guía la acción política, se permite al gobernante decisiones "inmorales", desde el punto de vista de la ética kantiana.

Weber sigue a Hume cuando se adhiere a la opinión sobre la imposibilidad de demostrar científicamente los juicios de valor moral. Y si no hay demostraciones estrictamente racionales, lo pertinente en la acción política es el beneficio práctico. Lo que sustrae de validez universal al principio de veracidad ${ }^{18}$ y permite las mentiras políticas, tuteladas dentro de una ética distinta a la del resto de la sociedad (a saber: la responsabilidad y no la convicción). Sin embargo, no

16 Weber, Max, 1997, p. 75.

17 Weber la llama "ética de los evangelios o de los fines absolutos", donde la alternativa es por "todo o nada".

18 Weber, Max, 1997, p. 70. 
anula principios comunes a toda ética, como "todo hombre desea su bien," o incluso "nadie debe hacer lo que no quiere que le hagan"; ya que, si bien nadie quiere que le mientan, se miente en política sólo cuando está en juego el bien común. ${ }^{19}$

Cuando Weber recomienda al político no guiarse por sus convicciones, propone hacer a un lado el imperativo categórico kantiano y ser responsable atendiendo a las consecuencias de sus decisiones y acciones. El gobernante, como profesional de la política, dispone de información exclusiva que lo compele a actuar responsablemente, sin apelar a sus convicciones, o sea al deber por el deber, al imperativo categórico. Nuevamente: Weber, conforme a Platón y contrario a Maquiavelo, propuso que la asignación de tareas y responsabilidades al gobernante lo obliga a cumplir con una moral distinta al del resto.

D. Karl Marx/Friedrich Engels: relación entre la falsa conciencia y el derecho a mentir

Cambiando el orden cronológico y la postura frente a la mentira política se encuentran Marx y Engels (especialmente en su obra La ideología alemana). Allí proponen que la conciencia humana solamente puede construirse de la mano de los medios de producción de vida, y cuando se disocia de ellos, entonces aparece la falsa conciencia o conciencia alienada. ${ }^{20}$ ¿Por qué habría de disociarse la conciencia que tiene el hombre de sí respecto de los medios de producción utilizados para crear su sustento? Marx/Engels responden que con el fin de ocultar la explotación de la mayoría en beneficio de unos cuantos. Esto no se logra a través de la fuerza (o no sólo), sino de una mentira política o explicación religiosa de la sociedad. ${ }^{21}$ así como la religión propone un ser eterno y más allá de este mundo

\section{Idem.}

20 Marx, Karl y Engels, Friedrich, Die deutsche Ideologie. Kritik der neuesten deutschen Philosophie in ihren Repräsentanten Feuerbach, B. Bauer und Stirner und des deutschen Sozialismus in seinen verschiedenen Propheten, Berlín, De Gruyter Akademie Forschung (libro electrónico), t. 5.

21 Idem. 
o de las condiciones concretas de vida, la mentira política que procura la alienación propone una explicación del orden social, ajena a las condiciones concretas de producción e inquebrantable o eterna. Esta visión religiosa de la sociedad es apocalíptica: si hay un cambio del orden social, sobreviene el caos. Ideas que afirman "la esencia del hombre es inalterable", "el núcleo de la sociedad es la familia nuclear" y "la propiedad privada es un derecho natural", son necesarias para justificar y eternizar un orden social determinado. ${ }^{22}$

La mentira política para Marx/Engels es compleja, no se explica simplemente como ocultar intencionalmente la verdad o decir conscientemente algo opuesto a ella, sino refiere al proceso de abstracción de las ideas, que consiste en separarlas de las condiciones concretas de producción que les dieron vida, convertirlas así en universalmente verdaderas o ahistóricas, disponer de un vínculo místico entre ellas y la realidad para que ni se expliquen ni se cuestionen, y, finalmente, crear los voceros de la verdad universal que confirmen su validez a través de su reiteración permanente a lo largo del tiempo. ${ }^{23}$ Todo esto trae aparejada la creación de una cultura de clase que uniforma los hábitos de consumo, coherente con la hegemonía de los mercados y la forma de producción. La cultura universal de clase establece la hegemonía de los valores y premia conforme a ellos el cine, la literatura o estipula los problemas que ameritan una solución científica. De esta forma, circunscribe el modo de entender la vida civilizada y la comunicación.

Para Marx/Engels, volver a una historia científica y a una conciencia despabilada o revolucionaria implica explicar las ideas a partir de las condiciones concretas de producción y a desenmascarar al engaño que otorga sostén y vida a una sociedad estratificada según los privilegios de una minoría.

Desde esta perspectiva, la mentira política se aproxima a la hipocresía y el autoengaño, porque condesciende con la mentira innoble a la vez que con el encubrimiento del apetito de poder. La mentira política funciona como una coartada de los cínicos respecto a sus propias ambiciones, tan propensos como la plebe a aceptar las opi-

22 Idem.

23 Idem. 
niones placenteras (en lugar de las verdades puras y duras) y a mentir, no por el peligro que representa la verdad, sino por el desprecio que sienten por los gobernados. Y como la verdad es indispensable para la libertad, la mentira política remite a una sociedad de amos y siervos.

Quienes antes y después de Marx/Engels desecharon igualmente el uso político de la mentira (después de la defensa realizada por los estoicos, en su afán de conciliar la filosofía con la mentira noble) fueron, por ejemplo, en el siglo IV, san Agustín, paladín de la verdad y enemigo acérrimo de la mentira. También debe mencionarse a Kant, quien en el siglo XVIII desechó la mentira política por representar una afrenta a la dignidad humana, al instrumentalizar y concebir al hombre como medio y no como fin. En la Inglaterra del siglo XIX, John Stuart Mill, siguiendo la tradición liberal de John Locke, David Hume, Adam Smith y David Ricardo, desdeñó la mentira y toda manipulación del comportamiento de los gobernados, y se precavió de ella reduciendo el Estado a su "mínima expresión" mediante la defensa de la libertad individual, la iniciativa privada y la participación de los ciudadanos en el poder.

Finalmente, la aceptación (justificación) o rechazo de la mentira política ofrece dos concepciones de ciudad: una autoritaria y otra democrática, una cerrada y otra abierta. En la segunda se favorece la divulgación de información veraz y la participación colectiva, así como la práctica del consenso y la organización libre y voluntaria. Por ello, los miembros de la sociedad abierta no podrán mentir en asuntos que atañen al destino de toda la comunidad, y en caso de hacerlo, dañarán el lazo de unión entre el sistema político y la vida social. Por eso - para Karl Popper — ${ }^{24}$ la mentira es el instrumento del Estado totalitario para mantener, vía engaño, el "bien de la sociedad".

Pese a esto, la mentira (como la verdad) constituye el material con el que se construye la realidad social. Y eso precisamente es lo que atañe a este escrito: dilucidar la manera en que opera esa construcción desde la información mendaz de los políticos.

24 Popper, Karl, “Der Zauber Platons”, en Die offene Gesellschaft und ihre Feinde, Stuttgart, UTB, 1992, vol. 1. 
JOSÉ MAÑÓN GARIBAY

\section{EL CARÁCTER DE LA COMUNICACIÓN POLÍTICA}

No es necesario insistir en que la publicidad (en general) es actualmente juzgada de manera radical: por un lado, sus críticos la condenan por representar todos los males de la sociedad de consumo, ${ }^{25} \mathrm{y}$, por otro, sus defensores acérrimos la proponen como la expresión artística y espiritual de nuestro tiempo. ${ }^{26}$ Que la publicidad no es ninguna cosa fácil de entender lo demuestran las discusiones entre estudiosos del mercado y creadores de la publicidad cuando intentan optimar las formas de presentar un producto en el mercado. ${ }^{27}$ Es aquí donde mejor se observan los desacuerdos acerca de la función y efectos que tiene y debe tener la publicidad en la construcción del sistema social de valores y participación social.

El poder de la publicidad es, por un lado, impensable sin los medios de comunicación masiva, porque gracias a ésta es aquélla omnipresente en nuestras vidas. Pero a la vez, el poder de la publicidad ha rebasado al de los medios de comunicación, al grado que la publicidad controla los medios de comunicación masiva. ${ }^{28}$ Basta con abrir un periódico, escuchar la radio o ver la televisión para tropezar con un sinnúmero de mensajes publicitarios. En algunas revistas, el bombardeo publicitario es tan grande que no se sabe si éstos están en función de aquéllas, o más bien, las últimas en función de los primeros. La relación publicidad/medios masivos de comunicación es tan compleja hoy día que muchos avances de la comunicación de masas son el resultado de la industria publicitaria (cuando en un principio más bien la publicidad era un subgénero de la comunicación de masas). ${ }^{29}$

Esto despierta el interés por saber cómo se da la influencia de los medios de comunicación de masas sobre la publicidad, y viceversa,

25 Wolfgang, Fritz Haug, 1980, p. 104.

26 Toscani, Oliviero, Die Werbung ist ein lächelndes Aas, Mannheim, Bollmann. Véase también, Schmidt, 1995, p. 30.

27 Toscani, Oliviero, capítulos I y II, 1996.

28 Luhmann, Niklas, 1995, p. 243, y en especial McLuhan, Marshall, 1995, pp. 122 y ss.

29 Cook, Guy, 1992, p. 53. 
de esta última sobre los medios de comunicación. ¿Desaparecerán los medios de comunicación en la publicidad? De otra manera: ¿se convertirá toda comunicación masiva en publicidad? ${ }^{30}$

\section{LA DINÁMICA DE CONSTRUCCIÓN DE LA REALIDAD SOCIAL Y LA POSVERDAD}

Para los teóricos de la comunicación Wulf D. Hund y Bärbel Kirchhoff-Hund, ${ }^{31}$ los medios de comunicación de masas no nacen ni dependen de la invención de la imprenta, la radio, la televisión o el Internet, sino antes bien, éstos son impensables fuera de una sociedad capitalista, y, sobre todo, sin el paso del capitalismo de libre competencia a otro de monopolio de mercado. Porque lo que está en juego en la comunicación de masas — según Wulf D. Hund y Bärbel Kirchhoff-Hund- es la necesidad de conformar la conciencia social del individuo. ¿Cómo se logra esto? Para estos autores, ${ }^{32}$ desempeñando tres funciones:

1. Tematización

2. Sincronización

3. Observación

Con lo primero, Wulf D. Hund y Bärbel Kirchhoff-Hund opinan que a través de los medios de comunicación se impone el valor o importancia a los temas sociales; con lo segundo, la estructura del tiempo social, diferenciando lo actual de lo obsoleto y porvenir. Y con lo tercero, la participación o inserción (colectiva) en la realidad social. A partir de estos tres aspectos es como se transforma la visión personal en pública, el interés local en general, la valoración subjetiva en objetiva. Por tanto, tematización, sincronización y observación constitu-

30 Baudrillard, Jean, 1978, pp. 38 y ss.

31 Hund, Wulf D. y Kirchhoff-Hund, Bärbel, 1980, p. 74. Ambos son representantes de la sociología materialista alemana. Wulf D. Hund es sociólogo y profesor en la universidad de Hamburgo.

32 Idem. 
JOSÉ MAÑÓN GARIBAY

yen la "opinión pública" (vox populi), ${ }^{33}$ que no es más que la realidad social común a todos los habitantes de una comunidad o la forma en que cada sociedad crea su realidad al crear sus sistemas de comunicación. ${ }^{34}$

Para enfocarme al tema medular de este trabajo sobre la publicidad política, su relación con los medios de comunicación de masas y su papel en la construcción de la conciencia (o falsa conciencia) social, es necesario ver cómo adquiere su valor fetiche.

\section{EL VALOR FETICHE DE LA COMUNICACIÓN POLÍTICA}

Según el profesor de la universidad libre de Berlín, Dr. Wolfgang Fritz Haug, ${ }^{35}$ la publicidad es muy antigua, pero gana su carta de naturalización con la producción industrial capitalista, ${ }^{36}$ porque aquí la producción en masa produce en exceso bienes de consumo: no sólo produce fuera de las necesidades sociales, sino, además, en cantidad desmesurada. Complementando las ideas de sus colegas Wulf D. Hund y Bärbel Kirchhoff-Hund, Fritz Haug propone que es precisamente esto lo que compele a diseñar campañas publicitarias que despierten el deseo de consumo. Por eso, la producción en masa sólo puede subsistir en la medida en que se produzcan, paralelamente a los bienes de consumo, los deseos por estos bienes, y esto sólo es posible con estrategias publicitarias.

33 Luhmann, Niklas, 1998, pp. 100 y ss. Luhmann afirma lo siguiente: "Ein Medium in diesem Sinne ist die «öffentliche Meinung» - gleichviel ob die Gesamtheit der Elemente psychisch als diffus verstreutes Aufmerksamkeitspotential verstanden wird, das durch Formenbildung temporär gebunden wird; oder sozial als Beiträge zu Themen der Kommunikation, wobei die Formenbildung im Bekanntsein (oder in der Unterstellbarkeit des Bekanntseins) liegt. Davon zu unterscheiden ist die Frage, welches soziale System dieses Medium produziert oder reproduziert - die Gesellschaft selbst oder ein eigens dafür ausdifferenziertes Funktionssystem. Nur dieses Funktionssystem soll mit dem Begriff der Massenmedien bezeichnet werden".

34 Luhmann, Niklas, 1998, p. 1098.

35 Haug, Wolfgang-Fritz, 1980, t. I, pp. 66 y ss.

36 Idem. 


\section{Valor fetiche y posverdad}

Mientras que para Fritz Haug la publicidad es inseparable de la producción en masa capitalista, para Clemens Wischermann ${ }^{37}$ ciertamente ésta surge de la economía capitalista, pero alcanza una autonomía con respecto a ella. Wischermann piensa que la producción en masa precisa de un consumo masivo, y considera - como Fritz Haug - que la publicidad es una pieza importante de la economía capitalista. Sin embargo, para Wischermann existe una cierta autonomía de la publicidad con respecto de la economía, porque si bien la primera es el reflejo de un estilo y de una cultura de consumo, también constituye el sistema de los valores de una sociedad (lo que rebasa el ámbito económico). ${ }^{38}$ Esto significa que en la publicidad los bienes de consumo tienen "valor propio" (un valor fetiche); ${ }^{39}$ o sea, un valor independientemente de su origen y con una capacidad de apropiarse del mundo llenándolo con su simbología y prometiendo satisfacer las carencias vitales. De esta forma, la publicidad funge como guía u orientación en la forma de organizar y vivir la vida toda.

El inicio de este mecanismo lo establece Wischermann ${ }^{40}$ entre 1850-1890 con la Gran Exposición Mundial de Londres (1851). En esta primera fase del desarrollo publicitario comienza la publicidad a constituir una cultura y una forma de vida, gracias a la autonomía que ganan los productos frente al consumidor (i. e., frente a sus necesidades) y a la apropiación de los valores indispensables para la socialización. En la segunda fase de su desarrollo, que tiene lu-

37 Wischermann, Clemens, 1995, p. 204.

38 Clemens Wischermann lo expresa así: "Hier wird die These aufgestellt, daß «consumerism», also Stil und Kultur einer Konsumgesellschaft, in der Werbung ausgebildet und dargestellt worden ist, schon bevor es einen gesellschaftlichen Übergang in eine Konsumgesellschaft mit Massenbasis überhaupt gegeben habe... [Demzufolge] war die Werbung also kein Zivilisationsnachfolger, sondern kreierte eine eigene neue Orientierungswelt, eine neue,Ordnung der Dinge "'. Cfr., 1995, p. 13.

39 Sobre el concepto de valor fetiche, cfr. Marx, Karl, Das Kapital. Erster Abschnitt: Waren und Geld. Kapitel I: die Waren. 4. der Fetischismus der Waren und ihr Geheimnis.

40 Ibidem, p. 228. 
JOSÉ MAÑÓN GARIBAY

gar en opinión de Wischermann hasta 1960, se desarrolla la publicidad completamente fuera de la estricta función comercial. Aquí ya se encuentran en primer plano la estética del anuncio y no más la influencia de éstos en los hábitos de consumo. Aquí es también cuando la publicidad crea sus propios valores y deja de reflejar los de la sociedad que le dio vida. Y, por último, aquí también es cuando se comienza a hablar de escuelas de publicidad, como antaño se habló de las escuelas de arte o de filosofía. En la última fase, a partir de los noventa y hasta nuestros días, el desarrollo publicitario es tal que amenaza a los valores establecidos, $i$. e., entra en conflicto como cultura de masa con la cultura tradicional, ${ }^{41}$ y se constituye - dice Wischrmann - en una estética de la vivencia mundana. De esta manera, llegamos, según Wischermann, ${ }^{42}$ a la autonomía total de la publicidad, donde a través de ella ya no se promueve un producto o su consumo, sino a ella misma para ser aceptada como parte de la expresión cultural (independiente de un pueblo determinado o época). Entonces, el anuncio aparece como un ícono o, para decirlo en el lenguaje actual, como un código universal para acceder al "presente" y a la actualidad social. Según Wischermann, la publicidad se desarrolló a partir de la economía capitalista hasta constituir una estética de consumo y una Weltanschaung: i. e., una forma de percibir y un deseo de poseer el mundo.

Con esta explicación del profesor de la universidad de Constanza, Clemens Wischermann, sobre la autonomía de la publicidad, es posible exponer el papel del fetiche como factor decisivo en la construcción de la realidad social, siguiendo los tres puntos enunciados por Wulf D. Hund y Bärbel Kirchhoff-Hund (i. e., tematización, sincronización, observación), pero enfocados a la comunicación/publicidad política en su relación 1) con los consumidores-votantes, 2) impacto en sus preferencias políticas, y 3) incitación a la participación activa o pasiva.

41 Un ejemplo de esto son las campañas publicitarias en los años noventa del italiano Oliviero Toscani, realizadas para la publicidad de ropa Benetton, donde presentaba a heridos de guerra, enfermos de sida o condenados a muerte en los Estados Unidos de Norteamérica.

42 Ibidem, p. 254. 


\section{LA CONSTRUCCIÓN DE LOS VALORES CIUDADANOS A TRAVÉS DE LA COMUNICACIÓN POLÍTICA}

Sobre el primer punto (i. e., la relación de la publicidad política con la vida real de los consumidores-votantes) es necesario entender que la publicidad no tiene exclusivamente el fin de promover el consumo de un producto político (programa de gobierno), sino obligar a adoptar una Weltanschauung. Esto queda claro cuando se entiende lo que implica la publicidad con relación a la aceptación social a través del consumo.

Tomemos como ejemplo el deseo de conquistar a alguien promoviendo nuestra propia imagen (o la imagen del candidato). Nadie impresiona a nadie con la simple referencia de ciertos datos biográficos tipo curriculum vitae. Más bien, lo que utilizaremos es una imagen, un icono, que tenga significado social relevante para la persona con quien hablamos. ¿Qué quiero decir con "significado social relevante"? Que a través del ícono o imagen que adoptemos, promovemos nuestras actitudes, formas de vida y reflexión sobre las cosas con el fin de que se nos reconozca como valioso. Y con el valor de ser introducimos algo más que inteligibilidad en nuestra forma de ser. Con el valor de ser... introducimos un atractivo para la persona de nuestras querencias (i. e., el votante). El valor de ser pretende más que dotar de sentido informativo; implica toda una estética de consumo o deseo de poseer el mundo como los describe la campaña política. ${ }^{43}$

Entonces, la publicidad política no trabaja en la promoción de una marca o idea con la información escueta del producto, sino con imágenes que encarnan valores y convicciones. La publicidad política comunica concepciones de vida a través de imágenes o íconos. Piénsese en la promoción de la estabilidad económica, el progreso social o el México de los pobres asociado a la imagen de una familia departiendo tranquilamente en la sala de su casa, una mujer joven al frente de su propia empresa o un niño indígena camino a la escuela. Con base en estos ejemplos se puede hacer una analo-

${ }^{43}$ Sobre la estética de la publicidad: Wischermann, Clemens, 1995, y Luhmann, Niklas, 1991. 
JOSÉ MAÑÓN GARIBAY

gía, de la mano de Bruno Bettelheim y su libro Los niños necesitan cuentos, ${ }^{44}$ diciendo que los hombres necesitan íconos, porque éstos proporcionan orientación en la vida al ser fácilmente inteligibles. ¿Qué significa estabilidad económica, progreso social o el México de los pobres? Las imágenes respecto a cada caso posibilitan identificar el amasijo de datos relevantes, y que constituyen políticamente el contexto económico, social e indígena del México deseable. ${ }^{45}$ Porque si se reflexiona sólo por un momento en todo lo que impacta nuestros sentidos al movernos por la ciudad (o el país), la cantidad de información en códigos múltiples que deben ser aprehendidos para saber lo que significa en la práctica estabilidad económica, progreso social o el México de los pobres, entonces se entiende la importancia comunicativa de las imágenes y la posibilidad que brindan para descifrar rápidamente esos significados pertinentes y ubicarlos en la jerarquía de nuestras prioridades políticas.

Así como un aviso de "PELIGRO" frente a un cesto de basura no es un mensaje significativo, como sí lo es frente a un socavón; de la misma forma, las imágenes de publicidad política (contextualizadas) nos enseñan a diferenciar rápidamente el sentido del sinsentido, lo importante de lo superfluo, lo correcto de lo obtuso, el bien del mal, lo políticamente correcto de lo desatinado. ${ }^{46}$

En un mundo saturado de información, la publicidad política presenta mensajes fácilmente descifrables que nos ayudan a encontrar el rumbo correcto, incluso fuera del mercado de consumo o elecciones presidenciales, ${ }^{47}$ porque las imágenes publicitarias

44 Bettelheim, Bruno, Kinder Brauchen Märchen, München, Deutscher Taschenbuch, 1980, $400 \mathrm{pp}$.

45 Idem.

46 Kaiser, Andreas, 1980, p. 124.

47 Evidentemente, los iconos o imágenes, que antaño orientaban nuestras vidas, pierden vigencia y pertinencia (ya sea los provenientes de la religión o de las ideologías políticas); por eso, puede hablarse de tiempo en tiempo de una crisis de iconos o imágenes del pasado, donde el vacío que dejan debe ser ocupado por otros nuevos. Esto significa que las imágenes publicitarias tienen un valor que va más allá de su sentido consumista o económico, porque ellas representan la actualidad del ideal de vida, lo que es menester hacer u omitir, en tiempos donde esa función ya no la cumple el ensayo o la arenga política. 
ofrecen el código con el que está programado nuestro politische Lebenswelt.

El segundo punto (i. e., el impacto de la publicidad en las preferencias políticas) va más allá que el anterior y afirma que la publicidad no simplemente presenta íconos o ideogramas para interpretar el mundo. En principio, pareciera que la "vida natural" del hombre (la vida sin publicidad) es hasta cierto punto tranquila y fácilmente saciable. Pero, más bien, ocurre que los consumidores-ciudadanos poseen un sinnúmero de deseos que luchan entre sí para ser satisfechos de manera imperante y exclusiva. Los deseos del consumidor político son contradictorios y lo inclinan en direcciones opuestas, según la naturaleza de cada deseo (por ejemplo, recolección de basura, agua potable suficiente, seguridad, areas verdes, mercados y escuelas a la mano, etcétera). Por un lado, cada deseo lucha por imponerse, y, por otro, el consumidor político tiene que controlar el impulso de sus distintos deseos para lograr un pensamiento y una vida social armónica. ${ }^{48}$ Ante estos deseos en pugna, las propuestas de la publicidad aparecen como un tranquilo coro de iglesia, jerarquizando los deseos y adjudicándoles su prioridad.

El problema de la vida política consiste en controlar todos los deseos que luchan prácticamente en un mismo momento por ser satisfechos. Regular deseos, jerarquizarlos, estructurarlos y darles su pertinencia adecuada, según el momento y situación, significa el éxito en la publicidad política.

El consumidor-votante necesita de ayuda para esa tarea, ${ }^{49}$ y esa ayuda viene de las imágenes publicitarias, como antaño venían de las imágenes religiosas. Hoy día son las campañas publicitarias las que otorgan ayuda a los consumidores, mostrando las imágenes del mundo deseable y del orden adecuado de nuestras propensiones. ${ }^{50}$ Por ejemplo: ¿no es el niño indígena, ataviado con su vestimenta típica y camino a la escuela bordeada de magueyes, la campaña publicitaria que mejor expresa el deseo de progreso y respeto a las tradiciones mexicanas? Aquí se observan deseos encontrados (y hasta contradictorios), progreso y tradición, en armonía perfecta.

48 Görke, Alexander y Kohring, Matthias, 1996, p. 423.

49 Luhmann, Niklas, 1998, p. 1098.

50 Idem. 
Entonces, las imágenes de la propaganda política presentan los deseos y las necesidades sociales y, además, la orientación pertinente en la forma como se concilian las propuestas en pugna. ${ }^{51}$

Sobre el tercer punto (i. e., la incitación de la publicidad política a la participación activa o pasiva) hay que decir que la vida cotidiana se ha vuelto un anuncio de productos diversos; porque así como la publicidad impregna de sentido el hecho de fumar, beber, conducir un auto, también la publicidad política impregna de sentido el hecho de elegir una idiosincrasia política. Cada cual practica en la vida diaria la publicidad de los productos que utiliza; $y$, sobre todo, al incorporarlos a su forma de ser cotidianamente, defiende y respalda una visión del mundo, de sus aspiraciones e ideales. ${ }^{52}$

Esto es claro hoy día en las redes sociales, donde cada cual es un publicista de sí mismo y de los productos que consume. Esto no se refiere a la defensa que antaño hacíamos de nuestras opiniones, ${ }^{53}$ sino a la inevitable campaña publicitaria que realizamos a diario al consumir una bebida, elegir una marca de cigarro, conducir un auto o votar por un candidato o partido. Cada actitud tiene un referente publicitario y manifiesta la concepción de vida creada por la publicidad, sea que elijamos ser un "fifí" o un "chairo" en nuestra vida. $^{54}$

La diferencia entre la publicidad presentada en los anuncios y la publicidad cotidiana que encarna en nuestras vidas reside en que la primera se hace presente como acción consciente, y la segunda, como reacción inconsciente. Esto es, así como el mejor anuncio de una cerveza es el gesto de frescura cuando se da el primer trago en el bar, de la misma manera en la vida diaria cuando un colega entrañable (futbolista o estrella de rock) se inclina por un candidato $y$ sus ideas, entonces es cuando el partido ha encontrado a su mejor publicista.

51 Wolfgang-Fritz, Haug. Hay que considerar que este autor no consideró la autonomía de la publicidad como sí lo hizo su compatriota Wischermann, 1996.

52 Baudrillard, Jean, 1989, pp. 34 y ss.

53 Ciertamente, defender una postura u opinión es, de alguna manera, recomendarla o hacerle publicidad.

54 "Fifí" es un equivalente de aburguesado, y su contrario, "chairo", significa popular o vulgar. Cfr., Haug, Wolfgang-Fritz, 1980. 
De esta forma, la publicidad está presente en todos los ámbitos de la vida, sus imágenes o íconos impactan en la vida cumpliendo una función orientadora, y al estructurar (ordenar y jerarquizar) los deseos, ayuda a tomar decisiones y realizar acciones; por tanto, dota de sentido al Lebenswelt político.

El mundo del consumidor-votante y el de la publicidad política no se encuentran en oposición, aunque ciertamente tampoco son lo mismo: el mundo de la publicidad política pretende orientar al consumidor-votante, y éste a su vez intenta participar en la vida pública según sus anhelos y valores "aspiracionales" fetiche. ${ }^{55}$

\section{CONCLUSIONES: COMUNICACIÓN POLÍTICA,} POSVERDAD Y CIUDADANÍA

Las críticas del llamado círculo rojo a la publicidad política han sido comúnmente que ésta no tiene que ver con los ciudadanos, porque 1) es ajena a la vida real de los consumidores-votantes; 2) no tiene impacto en las preferencias políticas; 3) no incita a la participación social. Esto sería justo si la publicidad política se redujera y permaneciera en espectaculares o anuncios de televisión, Internet, radio o periódicos; pero cuando se observa que moldea la actitud de los consumidores-votantes al transmitir imágenes representativas de valores aspiracionales (para llamarlos de alguna forma), entonces se entiende que la crítica es inapropiada. Es verdad que estos valores acusan una cierta contrariedad mutua, como el valor de la sociedad solidaria y competitiva, progresista y tradicional, verde-responsable y consumidora voraz de la moda, etcétera; pero el carácter aspiracional e irrealizable concilia los opuestos en tanto son valores deseables, pero no deseados.

La comunicación política, excediendo su condición de spot publicitario, no busca simplemente el voto, sino configurar una postura frente a la vida, organizando y jerarquizando los problemas sociales y ofreciendo un proyecto "aspiracional" de nación, lo que le confiere su condición de valor fetiche, incuestionable y eterno.

55 Schmidt, J. Siegfried, 1995, pp. 98 y ss. 
Si Platón dramatiza la situación de Sócrates cuando planteaba la mentira noble, es porque ésta le resultaba monstruosa. Además, no le parecía posible que alguien creyera en ella más allá de su infancia; por ello, recomendaba inculcarla en el periodo precrítico infantil y justificarla siempre en el bien común (VII. 520a-d). En contraposición, la mentira política hoy día es cínica y descarada. Esto puede operar en contra suya, pese a que los medios tecnológicos la hagan día a día más persuasiva.

Por otro lado, la consideración de Platón sobre la mentira noble (sobre todo como mito fundacional) consistía en que ésta debía enraizar en algo sobrehumano y estar situada en el pasado remoto, porque de esto dependía su credibilidad y falta de contradicción con el presente. En contraste, la seducción de la mentira política actual reside en ubicarla en un futuro anhelado (promesa perenne e inalcanzable), que, como el horizonte en altamar, permanece huidizo por más que se avance a su encuentro. En esto consiste su seducción: ser anhelada e inaccesible; especie de utopía/distópica.

\section{BIBLIOGRAFÍA}

ARENDT, Hannah, "El concepto de historia: antiguo y moderno," en Entre el pasado y el futuro. Ocho ejercicios sobre la reflexión política, Barcelona, Ediciones Península, 1996.

BAUdrillard, Jean, “Requiem für die Medien”, en BAUdrillard, Jean, Kool Killer oder Aufstand der Zeichen, Berlin, Merve, 1978.

BAUDRILlard, Jean, "Videowelt und fraktales Subjekt", en Ars Electronica. Philosophien der neuen Technologie, Berlín, Merve, 1989

BAUdrillard, Jean, Das System der Dinge. Über unser Verhältnis $z u$ den alltäglichen Gegenständen, Frankfurt am Main/New York, Campus, 1991.

Berger, Peter L. y Luckmann, Thomas, Die gesellschaftliche Konstruktion der Wirklichkeit, Frankfurt am Main, Fischer, 2001.

CASSIRER, Ernst, Antropología filosófica, México, Fondo de Cultura Económica, 1945. 
Cоoк, Guy, The Discourse of Advertising, London/New York, Routledge, 1992.

Enciclopedia Kleine Brockhaus, t. II (de la L hasta Z), Wiesbaden, Eberhard Brockhaus, 1950.

EnZENSBERGER, Hans Magnus (editor y autor), "Baukasten zu einer Theorie der Medien”, en EnZensberger, Hans Magnus, Kursbuch 20, Berlín, Matthes \& Seitz, 1970.

GidDens, Anthony et al., Soziologie, Viena, ediciones Nausner \& Nausner, 1995.

GöRKE, Alexander y KoHRING, Matthias, "Unterschiede, die Unterschiede machen: Neuere Theorieentwürfe zu Publizistik, Massenmedien und Journalismus", en Publizistik 41, Cuaderno 1, Springer Professional, 1996.

Hartmann, A. Hans y Haubl, Rolf, "Bilderflut und Sprachmagie”, en Fallstudien zur Kultur der Werbung, Opladen, Westdeutscher, 1992.

Haug, Wolfgang-Fritz, "Werbung und Konsum", en Systematische Einführung. Warenästhetik und kapitalistische Massenkultur, Berlín, Argument, 1980, t. I.

Heller, Eva, Wie Werbung wirkt. Theorien und Tatsachen, Frankfurt am Main, Fischer, 1984.

HöLscher, Barbara, Lebensstile durch Werbung? Zur Soziologie der Life-Style-Werbung, Opladen, Westdeutscher, 1998.

Horkheimer, Max y Adorno, W. Theodor, "Kulturindustrie", en Dialektik der Aufklärung, Frankfurt am Main, Fischer, 1988.

Hösle, Vitorio, Moral und Politik, München, C. H. Beck, 1997.

Hund, D. Wulf y KirchHoff-Hund, Bärbel, Soziologie der Kommunikation. Arbeitsbuch zu Struktur und Funktion der Medien. Grundbegriffe und exemplarische Analysen, Hamburg, Rowohlt, 1980.

KaISER, Andreas, Werbung, Theorie und Praxis werblicher Beeinflussung, München, Franz Vahlen, 1980.

KrIEgeskoRTE, Michael, 100 Jahre Werbung im Wandel: eine Reise durch die deutsche Vergangenheit, Köln, Du Mont, 1995. 
Luhmann, Niklas, Soziologische Aufklärung 3. Soziales System, Gesellschaft, Organisation, Wiesbaden, Springer, 1991.

Luhmann, Niklas, Die Realität der Massenmedien, Opladen, Westdeutscher, 1995.

Luhmann, Niklas, Die Gesellschaft der Gesellschaft, Frankfurt am Main, Suhrkamp, 1998, ts. I y II.

Maquiavelo, Nicolás, El príncipe, Barcelona, Biblioteca de los Grandes Pensadores, 2004.

Marcinkowski, Frank, Publizistik als autopoeitisches System. Politik und Massenmedien. Eine systemtheoretische Analyse, Opladen, Westdeutscher, 1993.

MARX, Karl y EngELs, Friedrich, Die deutsche Ideologie. Kritik der neuesten deutschen Philosophie in ihren Repräsentanten Feuerbach, B. Bauer und Stirner und des deutschen Sozialismus in seinen verschiedenen Propheten, Berlín, De Gruyter Akademie Forschung (libro electrónico), 1846, t. 5.

Mcluhan, Marshall, Die magischen Kanäle. Understanding Media, Basel, ECON, 1995.

Montani, Marco, "Paradise lost. Warum viele Unternehmen vom Internet enttäuscht sind", en Kursbuch Internet. Anschlüsse an Wirtschaft und Politik, Wissenschaft und Kultur, Mannheim, Bollmann, 1996.

Platón, La República, México, UNAM, Instituto de Investigaciones Filológicas, 2000.

SchmidT J., Siegfried, "Werbung zwischen Wirtschaft und Kunst", en J. Schmidt y B. SpIEß, (eds.), Werbung, Medien und Kultur, Opladen, Westdeutscher, 1995.

Strauss, Leo, Meditación sobre Maquiavelo, Madrid, Instituto de Estudios Políticos, 1964.

Toscani, Oliviero, Die Werbung ist ein lächelndes Aas, Mannheim, Bollmann, 1996.

Weber, Max, Politik als Beruf, Stuttgart, Reclam, 1997. 
WERNER Fuchs-Heinritz et al., Lexikon zur Soziologie, Wiesbaden, Springer, 2011.

Wischermann, Clemens, "Der kulturgeschichtliche Ort der Werbung”, en Borscheid, Peter y Wischermann, Clemens (eds.), Bilderwelt des Alltags, Stuttgart, Franz Steiner, 1995. 